\title{
BJMHR
}

British Journal of Medical and Health Research

Journal home page: www.bjmhr.com

\section{Outcome of Instrumentation in Subaxial Cervical Spine Injury- a Prospective case series}

\author{
Bipul Borthakur ${ }^{1}$, Aritra Bidyananda ${ }^{2 *}$, Siddhart Kumar ${ }^{3}$ \\ 1-Associate Professor, 2, 3-Post Graduate Trainee, Department of Orthopaedics, Assa \\ Medical College \& Hospital, Dibrugarh, Assam \\ 2-Department of Orthopedics, Assam Medical College \& Hospital, Dibrugarh 786004
}

\section{ABSTRACT}

Sub axial cervical spine accounts for about $65 \%$ of all cervical spine injuries. Adequate treatment can only be embarked upon after complete understanding of spinal biomechanics and the ability to determine the injury to various anatomical components of the spinal column. The current study discusses the treatment strategies and assesses the outcome of treatment in such injuries. 36 patients (22 males, 14 females; age range: 18-60 years) with unstable cervical spine injuries ( $\mathrm{C} 4$ to $\mathrm{C} 7$ ) with neurological deficit graded according to ASIA impairment scale were treated at Assam Medical College \& Hospital between June 2010 to September 2014. Patients with bilateral facet dislocation were treated with either posterior or anterior approach after failed preoperative traction. Unilateral facet dislocation was treated with lateral mass fixation or anterior plating. Patients with compressive flexion injury were treated with corpectomy, bone grafting/ cage and anterior plating. Vertical compression fractures were treated with corpectomy, bone grafting and anterior plating. The fusion time were 4 to 6 months and there was no residual instability of spine or loosening of the internal fixation at 12 months. Operative treatment of sub axial cervical spine injury decreases the complications related to prolonged immobilization and improves neurological outcomes. Both posterior and anterior surgical approaches are viable alternatives for treating these injuries with different indications and risk profiles. Identifying and understanding the injury, proper selection and planning of cases, preoperative optimization and thorough knowledge of anatomy is essential to obtain benefits of operative treatment.

Keywords: Sub axial, Cervical Spine, Instrumentation 


\section{INTRODUCTION}

A cervical spine injury occurs in $2 \%-3 \%$ of all blunt trauma victims. ${ }^{1}$ Injuries may range from minor ligament strains to complete fracture-dislocations resulting in severe spinal cord injury (SCI).Approximately two-third of all fractures and three-fourth of all dislocations involve the sub axial cervical spine. ${ }^{2}$ The sixth and seventh cervical vertebra together account for $39 \%$ of all cervical spine fractures. The most common causes of cervical spine injury are motor vehicular accidents (41\%), falls (27\%), violence (15\%), sports-related injuries (8\%), and fall of a heavy object on the head. ${ }^{3,4}$ A Spinal cord injury (SCI) is seen in $1.3 \%$ of all blunt trauma victims. ${ }^{5,6}$ Eighty percent of patients with associated SCI are males, and $40 \%$ are between 18 and 44 years of age. ${ }^{7}$ The C5-C7 region contributes to $60 \%$ of all SCI in patients with cervical spine trauma. Incomplete quadriplegia is found in $40 \%$ of patients with spinal cord involvement, complete paraplegia in $22 \%$, incomplete paraplegia in $22 \%$, and complete quadriplegia in $16 \%{ }^{6}$. The overall mortality rate from cervical spine injuries is approximately $6 \% .{ }^{8}$ The substantial motion of the cervical spine is what predisposes it to injury or instability events. The management of patients with cervical spine injuries involves three phases - pre-hospital care, emergency in hospital care, and definitive treatment. ${ }^{9}$ These injuries are often unstable injuries; however their optimal management is not always clear. In spite of all the efforts to classify these injuries, adequate treatment can only be embarked upon after complete understanding of spinal biomechanics and the ability to definitively determine the injury to the various anatomical components of the spinal column. The current study discusses the definitive treatment strategies and assesses the outcome of treatment in such injuries managed operatively.

\section{MATERIALS AND METHOD}

After obtaining due permission from the ethical committee of the institute, 36 patients with unstable cervical spine injuries with or without neurological deficit was included in the study. The patients were treated at the author's institute between June 2010 to September 2014 and were followed up for a period of 4 years prospectively. Preoperatively all patients were scored as per the Sub axial injury classification and scoring system (SLICS) and were found to have a score more than 5, suggesting need for surgical treatment. Patients with visceral injuries (head, chest, abdomen, etc.) and medical comorbidities were excluded from the study. An enquiry was also made about any previous injury to the cervical spine, previous cervical spine procedures, ankylosing spondylitis (AS), diffuse idiopathic skeletal hyperostosis (DISH), or other connective tissue disorders leading to ligamentous hyper laxity and if they were found then they were excluded from the study. 
There were 22 males and 14 females with an average age of 33.8 years (age range: 18-60 years). Fall from height and Road traffic accident was the mode of injury in 19 and 9 patients respectively. Injury while diving was seen in 8 patients (Table 1). After initial resuscitation with ATLS protocol and cervical spine immobilisation with Philadelphia hard cervical collar, the patients underwent a thorough neurological examination and impairment was graded as per ASIA impairment scale. In addition, while inspecting the patient, the cervical posture was assessed for identify any tenderness, step-offs or angular or rotational malalignments which could hint to dislocations or subluxation. The upper torso, head, and neck were also evaluated for signs of trauma as this can hint to the type of force applied to the cervical spine during the trauma event. Radiological investigations in the form of radiographs of cervical spine $-\mathrm{AP}$, lateral, open mouth and CT scan to further delineate bony injury were carried out next. Injured levels had the following distribution: 4 at $\mathrm{C} 4,14$ at $\mathrm{C} 5,13$ at $\mathrm{C} 6$, and 5 at $\mathrm{C} 7$. MRI studies were done for surgical planning given the excellent visualization of soft tissue compressive lesions. Disc herniations, hematomas and disco-ligamentous complex (DLC) injuries were evaluated with MRI. Preoperative skull traction with Crutchfield tongs was used to attempt reduction of dislocations and provide indirect decompression.

Table 1- Demographic parameters \& injury pattern in study subjects

\begin{tabular}{llllll}
\hline Parameter & & $\begin{array}{l}\text { Distractive } \\
\text { flexion } \\
\text { injury }\end{array}$ & $\begin{array}{l}\text { Compressiv } \\
\text { e flexion } \\
\text { injury }\end{array}$ & $\begin{array}{l}\text { Vertical } \\
\text { compressio } \\
\text { n injury }\end{array}$ & $\begin{array}{l}\text { Compressiv } \\
\text { e extension } \\
\text { injury }\end{array}$ \\
\hline $\begin{array}{l}\text { Number of } \\
\text { cases }\end{array}$ & 5 & 5 & 5 & 1 \\
Neurological & Fall from height & 2 & & & \\
status & RTA & 2 & 3 & 4 & 0 \\
& Diving & 1 & 2 & 1 & 0 \\
SLIC score & Complete & 0 & 0 & 0 & 1 \\
(mean) & Incomplete & 5 & 0 & 3 & 0 \\
& & 7.2 & 5 & 2 & 1 \\
\hline
\end{tabular}

Table 2- Injury pattern and treatment

\begin{tabular}{|c|c|c|c|c|c|c|}
\hline Case & $\begin{array}{l}\text { Age } \\
\text { (years) }\end{array}$ & Sex & $\begin{array}{l}\text { Injury } \\
\text { level }\end{array}$ & $\begin{array}{l}\text { Allen Ferguson } \\
\text { classification }\end{array}$ & $\begin{array}{l}\text { ASIA } \\
\text { impairment } \\
\text { scale }\end{array}$ & Surgery \\
\hline 1 & 38 & $\mathrm{M}$ & C5-6 & $\begin{array}{l}\text { Distractive flexion } \\
\text { (stage } 1 \text { ) }\end{array}$ & Grade C & $\mathrm{ACDF}$ \\
\hline 2 & 40 & M & $\mathrm{C} 5$ & $\begin{array}{l}\text { Compressive flexion } \\
\text { (stage 5) }\end{array}$ & Grade C & $\mathrm{ACCF}$ \\
\hline 3 & 30 & M & C4-5 & $\begin{array}{l}\text { Compressive } \\
\text { extension (stage 5) }\end{array}$ & Grade C & $\begin{array}{l}\text { Anterior discectomy }+ \\
\text { posterior wiring \& fusion }\end{array}$ \\
\hline 4 & 31 & M & C6 & $\begin{array}{l}\text { Compressive flexion } \\
\text { (stage 5) }\end{array}$ & Grade D & $\mathrm{ACCF}$ \\
\hline 5 & 33 & M & C5 & $\begin{array}{l}\text { vertical compression } \\
\text { (stage } 3 \text { ) }\end{array}$ & Grade A & $\mathrm{ACCF}$ \\
\hline
\end{tabular}




\begin{tabular}{|c|c|c|c|c|c|c|}
\hline 6 & 24 & $\mathrm{~F}$ & $\mathrm{C} 5-6$ & $\begin{array}{l}\text { Distractive flexion } \\
\text { (stage 2) }\end{array}$ & Grade $\mathrm{C}$ & ACDF \\
\hline 7 & 22 & M & $\mathrm{C} 4-5$ & $\begin{array}{l}\text { Distractive flexion } \\
\text { (stage 2) }\end{array}$ & Grade D & $\begin{array}{l}\text { Posterior stabilisation with } \\
\text { spinous wiring+ posterior } \\
\text { fusion }\end{array}$ \\
\hline 8 & 45 & $\mathrm{~F}$ & $\mathrm{C} 7$ & $\begin{array}{l}\text { Vertical compression } \\
\text { (stage } 3 \text { ) }\end{array}$ & Grade A & $\mathrm{ACCF}$ \\
\hline 9 & 18 & M & C6 & $\begin{array}{l}\text { Compressive flexion } \\
\text { (stage } 4 \text { ) }\end{array}$ & Grade C & $\mathrm{ACCF}$ \\
\hline 10 & 30 & $\mathrm{~F}$ & C6 & $\begin{array}{l}\text { Compressive flexion } \\
\text { (stage 5) }\end{array}$ & Grade C & $\mathrm{ACCF}$ \\
\hline 11 & 39 & $\mathrm{~F}$ & $\mathrm{C} 5$ & $\begin{array}{l}\text { Vertical compression } \\
\text { (stage } 3 \text { ) }\end{array}$ & Grade D & $\mathrm{ACCF}$ \\
\hline 12 & 32 & M & $\mathrm{C} 5$ & $\begin{array}{l}\text { Distractive flexion } \\
\text { (stage } 3 \text { ) }\end{array}$ & Grade D & $\mathrm{ACDF}$ \\
\hline 13 & 30 & M & $\mathrm{C} 5$ & $\begin{array}{l}\text { Vertical compression } \\
\text { (stage } 3 \text { ) }\end{array}$ & Grade C & $\mathrm{ACCF}$ \\
\hline 14 & 34 & M & $\mathrm{C} 5$ & $\begin{array}{l}\text { Compressive flexion } \\
\text { (stage } 4 \text { ) }\end{array}$ & Grade C & $\mathrm{ACCF}$ \\
\hline 15 & 36 & M & C6 & $\begin{array}{l}\text { Vertical compression } \\
\text { (stage } 3 \text { ) }\end{array}$ & Grade A & $\mathrm{ACCF}$ \\
\hline 16 & 60 & M & $\mathrm{C} 7$ & $\begin{array}{l}\text { Distractive flexion } \\
\text { (stage } 3 \text { ) }\end{array}$ & Grade C & $\begin{array}{l}\text { Posterior stabilization with } \\
\text { spinous wiring }+ \text { posterior } \\
\text { fusion }\end{array}$ \\
\hline
\end{tabular}

The injuries were classified according to Allen and Ferguson mechanistic classification ${ }^{10}$. Grossly four types of injuries i.e., distractive flexion, compressive flexion, compressive extension and vertical compression were noted. Among the 15 patients of distractive flexion injury, stage 1 with posterior ligamentous failure was seen in 4 patient, stage 2 i.e., unilateral facet dislocation injuries was seen in 5 patients and stage 3 i.e., bilateral facet dislocation injuries were present in 6 patients. Compressive flexion injuries were present in 12 patients of whom 5 were in stage 2 and 5 in stage 5 . Compressive extension stage 5 injury was detected in 1 patient. Stage 3 vertical compression injury was present in 8 patients. (Table 1,2)

Patients with bilateral facet dislocation were treated with either posterior or anterior approach. Similarly, unilateral facet dislocation was treated with posterior wiring or anterior plating. Patients with compressive flexion injury were treated with corpectomy, bone grafting/ cage and anterior plating. Vertical compression fracture was treated with corpectomy, bone grafting and anterior plating. 21 out of 36 patients (58.32\%) were operated within 7 days and the rest were operated within 14 days.

Patients were followed up at $6,12,18$ weeks of operation for the first postoperative year. In the second postoperative year follow-up was done at 6 months interval. During each follow-up clinical and radiological parameter were measured - bone fusion and internal 
fixation condition were observed by $x$-ray and the neurological recovery was measured by ASIA impairment scale.

\section{RESULTS AND DISCUSSION}

Most common mechanism of injury (60\%) is accidental fall from height. In this study mean age of the patients was 33.8 years. C5 is the most commonly involved vertebra (38.8\%). Distractive flexion followed by compressive flexion and vertical compression injury were the most common injury patterns in the series. An average of one grade improvement in ASIA impairment scale was seen in majority (23 out of 16, 63.8\%) of cases. (Table 3) We found $100 \%$ fusion rate in both anteriorly and posteriorly treated patients. Time required for fusion ranged from 4 to 6 months. Patients had a mean kyphotic angle of $24.5^{\circ}$ (ranges $9^{\circ}$ to $36^{\circ}$ ) and the mean translation of vertebra in sagittal plane was $5 \mathrm{~mm}$ (ranges from $2 \mathrm{~mm}-8 \mathrm{~mm}$ ). Mean kyphotic angle after operation was $2.7^{\circ}$ (ranges from $0^{\circ}$ to $5^{\circ}$ ) and sagittal plane translation was almost corrected. In this study one scale improvement in ASIA impairment scale occurred in $64 \%$ patients of anterior group and 50\% improvement occurred in posterior group. There was also no instability of vertebras or loosening of the internal fixation at 12 months. One patient developed superficial wound infection that had undergone posterior surgery and one developed dysphagia following anterior surgery which resolved spontaneously. Two patients developed pain in the do-nor site following bone grafting. There was no incidence of vertebral artery injury however, 1 patient expired due to postoperative sepsis.

Table 3- Neurological recovery post-surgery

\begin{tabular}{llll}
\hline $\begin{array}{l}\text { Preoperative } \\
\text { ASIA scale }\end{array}$ & $\begin{array}{l}\text { No of } \\
\text { cases }\end{array}$ & $\begin{array}{l}\text { Postoperative ASIA } \\
\text { scale at 2 year } \\
\text { follow up }\end{array}$ & No of cases \\
\hline A & 3 & A & 2 \\
& & B & 1 \\
C & 9 & C & 2 \\
& & D & 7 \\
D & 4 & E & 0 \\
& & D & 2 \\
\end{tabular}
Abbreviation:
1. ACDF: Anterior cervical discectomy \& Fusion
2. ACCF: Anterior Corpectomy \& cage fixation
3. ASIA: American Spinal Injury Association
4. RTA: Road traffic Accident 


\section{DISCUSSION}

Sub axial cervical spine injury can be a debilitating injury that often affects the younger population. The most common mechanism of injury is accidental fall from height as also described by $\mathrm{Hu}$ et al ${ }^{11}$. C5 is level most commonly affected in this series as it is a region associated with substantial amount of motion ${ }^{12}$. Many such injuries require operative intervention though no conclusion is reached regarding the relationship between the improvement of paralysis and the timing of surgery ${ }^{13}$.

Overall studies have shown that SLIC (Sub axial injury classification and scoring system) is reproducible and reliable and aids in selecting candidates for surgical intervention ${ }^{14}$. However, several of these studies reporting good to excellent results are retrospective and there is a paucity of prospective data supporting these results. More recent studies have demonstrated poor intra observer rating with regard to morphological classification with only average agreement on the integrity of the DLC questioning treatment algorithms based solely on scoring systems ${ }^{12}$. In the present series SLICS score favoured surgical intervention in all cases eventually operated but it was used only as an adjunct in selecting cases for operative intervention as the final decision rested with operating surgeon.

Distraction flexion was a common mechanism seen in this series and this injury may lead to mild to very severe cord injury. These are the most common injury patterns in Allen and Ferguson's classification ${ }^{10}$. The mildest form of injury in this class is facet subluxation and can be missed on initial evaluation which may present later as late occult instability, due to the poor healing potential of posterior ligamentous injuries ${ }^{15}$. A ligamentous injury or larger facet fragment with displacement may warrant operative stabilization. Spector et al. evaluated factors on CT scanning found that unilateral facet fractures that involved greater than $40 \%$ of the absolute height of the intact lateral mass or fragments that were $>1 \mathrm{~cm}$ were at increased risk of failure of nonoperatively treatment and hence operative treatment is recommended ${ }^{16}$ Stage 3 distraction flexion injury (bilateral facet joint dislocation) has been described as a potentially lethal injury ${ }^{17}$. We encountered two such cases in our series and these awake and conscious patients underwent careful preoperative attempted reduction of dislocation. Once dislocation is reduced by pre-operative traction, operative stabilization has been demonstrated to be superior to non-operative management in maintaining reduction ${ }^{13,15,17}$. Operative stabilization can be performed anteriorly with discectomy and plating or posteriorly with lateral mass screws fixation or facet/ spinous process wiring. The advantages of anterior stabilization are that it allows adequate decompression in a supine position by removal of a disc herniation and may save a fusion level ${ }^{14,17}$. Posterior stabilization restores the posterior tension band but typically requires an additional level of fixation however it may be a much 
more stable construct ${ }^{17}$. Hence the treatment may have to be individualised and may require both anterior and posterior approaches keeping in mind that anterior approach provide better visualisation for decompression due to herniated discs and posterior fixation based on rigid fixation techniques can tackle the dislocation and associated injuries directly ${ }^{18}$. Anterior approaches may be associated with fewer wound complications but at the risk of postoperative swallowing difficulties ${ }^{12}$. A preoperative MRI to rule out significant disc herniation before intraoperative reduction is recommended to avoid posterior disc migration and neurological worsening.

Flexion-compression injuries is a continuum of injury patterns, with minor degrees of trauma which can produce simple vertebral body compression fractures and more severe injuries resulting in tear drop fracture and the most severe injury results in posterior subluxation of posterior vertebral body into the canal, acute kyphosis, disruption of the ALL, PLL and posterior ligaments ${ }^{13}$. The primary distinction between tear drop fractures and burst fractures is compression of the middle column as seen in burst fractures. However, that both burst fractures and tear-drop dislocation fractures should be treated with an anterior fusion when possible as superior decompression is achieved from the anterior approach leading to superior clinical results ${ }^{19}$.

Hence the goal in treatment of cervical injuries is to relieve compression and to re-store the structural integrity of the spine as post-traumatic instability of the spinal column delays rehabilitation and leads to secondary neural compromise causing worsening of spinal cord deficits. Although the general treatment principles of spinal surgery are well known, specific treatment approach and strategies need to be individually assessed according to injury pattern.

\section{REFERNCES}

1. Lowery DW, Wald MM, Browne BJ, Tigges S, Hoffman JR, Mower WR; NEXUS Group. Epidemiology of cervical spine injury victims. Ann Emerg Med 2001; 38:126.

2. Goldberg W, Mueller C, Panacek E, Tigges S, Hoffman JR Mower WR; NEXUS Group. Distribution and patterns of blunt traumatic cervical spine injury. Ann Emerg Med 001; 38:17-21.

3. Burke DA, Linden RD, Zhang YP, Maiste AC, Shields CB. Incidence rates and populations at risk for spinal cord injury: A regional study. Spinal Cord 2001; 39:2748. 
4. Nobunaga AI, Go BK, Karunas RB. Recent demographic and injury trends in people served by the Model Spinal Cord Injury Care Systems. Arch Phys Med Rehabil 1999; 80:1372-82.

5. Tator $\mathrm{CH}$, Duncan EG, Edmonds VE, Lapczak LI, Andrews DF. Changes in epidemiology of acute spinal cord injury from 1947 to 1981. Surg Neurol 1993; 40:207-15.

6. National Spinal Cord injury Statistical Centre. Spinal *cord injury facts and figures at a glance. Birmingham, AL: Publication of the National Spinal Cord Injury Statistical Centre; 2011.

7. Baaj AA, Uribe JS, Nichols TA, Theodore N, Crawford NR, Sonntag VK, et al. Health care burden of cervical spine fractures in the United States: Analysis of a nationwide database over a 10-year period. J Neurosurg Spine 2010; 13:61-6.

8. Sokolowski MJ, Jackson AP, Haak MH, Meyer PR Jr., Sokolowski MS. Acute mortality and complications of cervical spine injuries in the elderly at a single tertiary care centre.

9. Zaveri G, Das G. Management of sub-axial cervical spine injuries. Indian J Orthop $2017 ; 51: 633-52$

10. Allen B, Ferguson R, Lehmann T, et al. A mechanistic classification of closed, indirect fractures and dislocations of the lower cervical spine. Spine. 1982; 7:1982.

11. Hu R MCBC. Epidemiology of incident of spinal fracture in a complete population. Spine. 1996; 21.

12. Sub axial cervical spine trauma. Curr Rev Musculoskelet Med. 2016; 9: p. 496-504.

13. Sarkar PS, Mukopadhyay KK, Bera AK, Latif A. Operative outcome of unstable lower cervical fracture dislocation by lateral mass screw fixation or anterior plating. Journal of Indian Medical Association. 2012; 110(11).

14. Williams KD. Fractures, dislocations and fracture dislocations of the spine. In Canale ST, Beaty JH, editors. Campbell's operative orthopaedics. 12th ed.: Elsevier; 2013. p. 1593.

15. Torretti JA, Sengupta DK. Cervical spine trauma. Indian journal of Orthopaedics. 2007; 41(4).

16. Specter LR. Use of computed tomography to predict failure of nonoperatively treatment of unilateral facet fractures of the cervical spine. Spine. 2006; 31: p. 282735.

17. Cotler M, et al. Closed reduction of traumatic cervical spine dislocation using traction weights up to 140 pounds. Spine. 1993; 18: p. 386-390. 
18. Jaoquim AF, Patel AA. Subaxial cervical spine trauma- evaluation and surgical decision making. Global spine journal. 2014; 4: p. 63-70.

19. Toh E, Nomura T, Watanabe M. Surgical treatment for injuries of the middle and lower cervical spine. International Orthopaedics (SICOT). 2006; 30: p. 54-58.

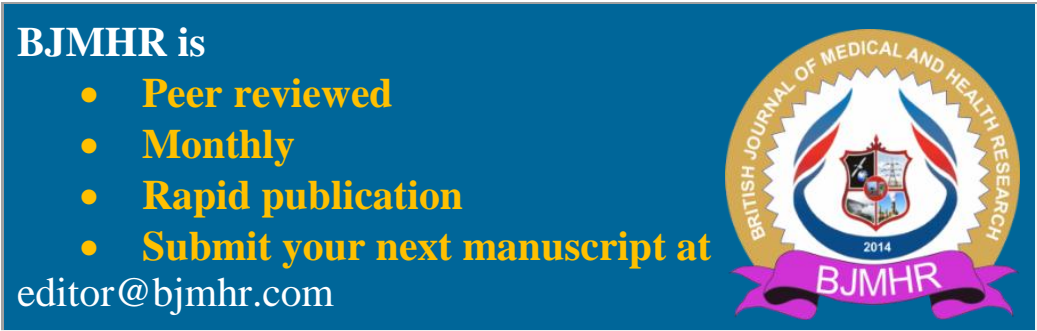

